\title{
The immunological regulation of cancer cachexia and its therapeutic implications
}

\author{
Janice Miller ${ }^{1}$, Barry J. A. Laird², Richard J. E. Skipworth ${ }^{1}$ \\ ${ }^{1}$ Clinical Surgery, Royal Infirmary of Edinburgh, University of Edinburgh, Edinburgh EH16 4SA, UK. \\ ${ }^{2}$ Edinburgh Palliative and Supportive Care Group, University of Edinburgh, Western General Hospital, Edinburgh EH4 2XU, UK.
}

Correspondence to: Dr. Richard J. E. Skipworth, Clinical Surgery, Royal Infirmary of Edinburgh, University of Edinburgh, 51 Little France Crescent, Edinburgh EH16 4SA, UK. E-mail: richard.skipworth@nhslothian.scot.nhs.uk

How to cite this article: Miller J, Laird BJA, Skipworth RJE. The immunological regulation of cancer cachexia and its therapeutic implications. J Cancer Metastasis Treat2019;5:68. http://dx.doi.org/10.20517/2394-4722.2019.001

Received: 7 Apr 2019 First Decision: 1 July 2019 Revised: 11 Sep 2019 Accepted: 25 Sep 2019 Published: 30 Sep 2019

Science Editor: Bingliang Fang Copy Editor: Cai-Hong Wang Production Editor: Tian Zhang

\begin{abstract}
Cachexia affects the majority of patients with advanced cancer. It leads to poor surgical and oncological outcomes, and negatively affects quality of life. It has long been reported that components of the host immune system, including pro-inflammatory cytokines such as IL-1 $\alpha, I L-6$, TNF- $\alpha$ and INF- $\gamma$, participate in the syndrome of cachexia. Yet therapeutic targeting of these pro-inflammatory factors has not yielded meaningful improvements in cachexia management. More recently, the impact of immune cells in the tumour mass (tumour-associated macrophages) and host circulation (myeloid suppressor cells) has garnered much interest with regards to their role in immune tolerance in cancer. However, their role in the generation of systemic inflammation and cancer cachexia is underexplored and outstanding questions remain. This review summarises the key mediators and targets of immune dysfunction in cancer cachexia. Here we describe the host response including skeletal muscle wasting; highlight the current knowledge gap areas; and report the results of previously trialled immunotherapies. A greater understanding of complex interaction between the tumour, immune system and peripheral tissues in the genesis and maintenance of cancer cachexia is a key step in $n$ identifying future therapeutic targets.
\end{abstract}

Keywords: Cancer cachexia, interleukins, macrophages, immunotherapy

\section{INTRODUCTION}

Cachexia is "a multifactorial syndrome defined by an ongoing loss of skeletal muscle mass (with or without loss of fat mass) that cannot be fully reversed by conventional nutritional support and leads to progressive

cc) (i) (c) The Author(s) 2019. Open Access This article is licensed under a Creative Commons Attribution 4.0 International License (https://creativecommons.org/licenses/by/4.0/), which permits unrestricted use sharing, adaptation, distribution and reproduction in any medium or format, for any purpose, even commercially, as long as you give appropriate credit to the original author(s) and the source, provide a link to the Creative Commons license, and indicate if changes were made.

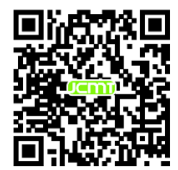


functional impairment" ${ }^{\text {, }}$. Cachexia has a negative impact on a large proportion of patients with advanced cancer with it contributing to high levels of morbidity and mortality ${ }^{[2]}$. Although there still remains some debate over the formal definition of cancer cachexia, it is characterized by unintentional weight loss, muscle wasting, anorexia and fatigue ${ }^{[3]}$. Systemic inflammation is a key driver of cancer cachexia and has been advocated as a core nutritional assessment in patients with cancer ${ }^{[4,5]}$. Pro-inflammatory cytokines are activated by the tumour mass, and act both centrally (through anorexia) and peripherally (by skeletal muscle wasting) to result in host nutritional depletion ${ }^{[6]}$. Tumour and host-derived factors thus lead to a chronic inflammatory and impaired immune state ${ }^{[7]}$. Immunosuppression is a large problem in cachectic cancer patients contributing to reduced responses to surgical and oncological outcomes ${ }^{[8]}$. The dysfunction of the immune system is complex and involves multiple mechanisms characterised by a reduction in monocyte, macrophage, dendritic and natural killer (NK) cell function, ultimately leading to susceptibility to infections, and therefore, an overall increase in morbidity ${ }^{[9]}$.

In short, it has long been apparent that systemic inflammation plays a role in the pathogenesis of cancer cachexia. The successful therapeutic targeting of systemic inflammation requires a better understanding of the involved mediators and the link between tumour and immune tissues. This review aims to describe some of the key elements of immune dysfunction in cachexia and give an overview of previously trialled immunotherapies.

\section{PRO-CACHECTIC CYTOKINES}

TNF- $\alpha$

TNF- $\alpha$ (previously known as "cachectin" ${ }^{[10]}$ ) was initially held responsible for causing most of the metabolic derangements and clinical features of cachexia. TNF- $\alpha$ is released by many types of cell, including activated macrophages, CD4+, neutrophils, mast cells, eosinophils and neurons. In particular, it can be produced by tumour, immune and stromal cells to induce growth and survival advantage in the tumour microenvironment ${ }^{[11]}$. Its expression can ultimately lead to anorexia, muscle and adipose wasting, loss of appetite, increased energy expenditure and insulin resistance in both patients with various types of cancer, and the Colon-26 carcinoma mouse model of cancer cachexia $(\mathrm{C} 26)^{[12]}$. Many of the effects of TNF- $\alpha$ arise through activation of $\mathrm{NF}_{\kappa} \mathrm{B}$, which in turn leads to activation of the ubiquitin-proteasome pathway and skeletal muscle degradation ${ }^{[13]}$. It also acts to induce oxidative stress and nitric oxide species (NOS). Experimental evidence suggests TNF- $\alpha$ can induce adipose wasting in white adipose tissue through inhibition of lipoprotein lipase (LPL), suppression of transcription and promotion of lipolysis ${ }^{[14,15]}$ as well as stimulation of thermogenesis through increased expression of UCP2 and UCP3 in skeletal muscle.

The role of TNF- $\alpha$ in mediating many of the effects of cancer cachexia was initially supported by evidence that intraperitoneal injection of soluble recombinant human TNF-receptor antagonist was able to improve food intake and thus lead to weight gain in tumour-bearing rats ${ }^{[16]}$. Lewis lung carcinoma (LLC) mice deficient in TNF- $\alpha$ receptor protein type 1 showed a reduction in muscle wasting compared with LLC wild-type mice despite similar levels of TNF- $\alpha$ being detected in the serum ${ }^{[17]}$. Treatment with antioxidants or NOS inhibitors was shown to increase body weight and prevent muscle wasting in mice ${ }^{[18]}$. Despite this, TNF inhibition alone in animals has not been shown to be sufficient to reduce or reverse the cachectic process indicating that, although it is involved in the pathogenesis of cancer cachexia, it is not solely responsible ${ }^{[19]}$.

Studies in patients with cancer, have also not been successful. In particular adipocytes taken from cancer patients, showed no decrease in LPL messenger RNA (mRNA) or LPL enzyme activity ${ }^{[20]}$. Some studies have shown raised TNF- $\alpha$ levels in the serum of patients with pancreatic cancer associated with weight loss, whereas other studies in patients with terminal cancer showed no association between TNF- $\alpha$ and weight $\operatorname{loss}^{[21,22]}$. Others have shown that TNF- $\alpha$ correlates with stage of disease or tumour size rather than degree 
of weight loss ${ }^{[23]}$. These discrepancies between studies may be due to differences in measuring techniques, possible auto or paracrine roles for TNF- $\alpha$ in adipose tissue, or heterogeneity between patients, sexes and tumours.

In summary, TNF- $\alpha$ is involved in systemic inflammation, but as cachexia is likely to be multifactorial, it is difficult to implicate TNF- $\alpha$ as the sole cause. More clinical studies are required to fully isolate its effects in patients.

\section{Interferon gamma}

Interferons are multifunctional cytokines that block viral infections and affect cell proliferation and differentiation ${ }^{[24]}$. Interferon gamma (IFN $\gamma$ ) is produced by activated $\mathrm{T}$ and $\mathrm{NK}$ cells, and is arguably the most potent monocyte-macrophage activating factor ${ }^{[25]}$. In the context of cancer, tumour-infiltrating lymphocytes (TILs), which have shown to be of particular importance in tumour immunosurveillance, are the main source of IFN $\gamma^{[26]}$. There is an overwhelming body of evidence for both beneficial and detrimental roles of IFN $\gamma$ in a range of diseases, including cancer. However, its role in patients with cachexia is a relatively underexplored area.

Several animal studies have indicated a central role for IFN $\gamma$ in the pathogenesis of cachexia. Central administration of rat interferon resulted in decreased food intake whereas peripheral administration failed to do $\mathrm{so}^{[27]}$. Mice overexpressing IFN $\gamma$ producing tumour cells developed loss of body weight, atrophy of adipose tissue, and reduced appetite, all of which were then reversed by pre-treatment of the mice with anti-IFN $\gamma$ antibodies ${ }^{[28]}$. Mice with LLC also demonstrated a reduction in weight loss after treatment with anti-IFN $\gamma$ antibody, significantly reducing fat wasting in particular ${ }^{[29]}$. In rats that had received transplants of MCG 101 sarcoma, anti-IFN $\gamma$ antibody reduced weight loss, but the effect of treatment was shortlived $^{[30]}$. Similarly to TNF- $\alpha$, IFN $\gamma$ has been shown to inhibit LPL activity in adipocyte cells in vitro, as well as that of glycerol phosphate dehydrogenase in cultures of rat adipocytes ${ }^{[31]}$.

\section{IL-1 $\alpha$}

Levels of IL-1 $\alpha$ have been shown to be increased in animal models of cachexia. It is thought to cause similar effects to that of TNF- $\alpha^{[32]}$. IL- $1 \alpha$ is a pro-inflammatory cytokine produced mainly by macrophages and endothelial cells and is known for being a trigger of the acute phase response, thus playing a role in cancer pathogenesis, as well as shock and autoimmune disorders ${ }^{[33]}$. In a similar fashion to other cytokines discussed, it is also able to inhibit LPL activity and stimulate lipolysis in cultured adipocytes ${ }^{[34]}$. The ability of IL-1 to induce anorexia is thought to be due to a central effect on appetite suppression ${ }^{[35]}$ involving blockade of neuropeptide Y. It also increases plasma concentrations of tryptophan and serotonin leading to early satiety and suppression of hunger ${ }^{[36]}$.

Again, there is evidence for the role of IL- $1 \alpha$ in animal models of cachexia, but little in humans. IL-1 $\alpha$ can induce cachexia and anorexia in rats. IL- $1 \alpha$ treated rats showed loss of body weight. Administration of IL- $1 \alpha$ receptor antagonist (IL-1 $\mathrm{r} \alpha$ ) to tumourbearing rats however, did not result in any improvement in body weight ${ }^{[37]}$. Following direct tumour injection with IL-1r $\alpha$, C26 mice demonstrated significantly reduced weight loss (without an effect on tumour burden) compared with mice who had systemic injection ${ }^{[38]}$. Cultures of C26 cells also demonstrated raised levels of IL- 6 after stimulation with IL-1 $\alpha$, which were suppressed by monoclonal antibody to IL- $6^{[38]}$. In tumour samples from patients undergoing surgical resection for upper gastrointestinal malignancy, IL-1 $\beta$ and IL- 6 were also significantly overexpressed in the cancer specimens, at both mRNA and protein levels, compared with control mucosa. Protein levels were seen to correlate with CRP, indicating that tumour may be the source of IL-1 $\beta^{[39]}$. 


\section{IL-1 $\beta$}

IL- $1 \beta$ is a proinflammatory cytokine released by macrophages. It regulates the expression of other cytokines including IL- 6 and IL-12. Recently, the loss of p53 in cancer cells from breast cancer mouse models have been shown to induce the secretion of WNT ligands that stimulate tumour associated macrophages (TAMs) to produce IL-1 $\beta$, therefore helping to drive systemic inflammation. Macrophages were prevented from secreting IL- $1 \beta$ by pharmacological and genetic blockade of WNT secretion in p53 null cancer cells. This blockade also resulted in decreased neutrophilic inflammation and metastasis formation ${ }^{[40]}$. These findings therefore suggest an important potential future role for personalised immune therapy in patients with cancer cachexia.

IL-1 $\beta$ has also been better associated with the clinical features of cachexia such as anorexia, weight loss and sarcopenia than other cytokines such as IL- 6 in a study of 83 advanced cancer patients ${ }^{[41]}$. Patients with gastric cancer cachexia have also been shown to have a higher prevalence of IL-1 B+3954 T allele than those without indicating that patient genotype plays a role on immunological regulation of cancer cachexia ${ }^{[42]}$.

\section{IL-6}

IL-6 can target adipose tissue, skeletal muscle, gut, and liver tissue, which can all affect cachectic patient body composition. It signals through the membrane bound receptor gp130 found in most tissues in the body ${ }^{[43]}$. Once bound to its receptor, it activates JAK tyrosine kinase leading to phosphorylation of tyrosines and the binding of STAT proteins. STAT proteins can translocate to the nucleus and increase the transcription of genes involved in immune function, cell proliferation, differentiation and apoptosis ${ }^{[43]}$.

Several mouse cancer models have clearly demonstrated that blocking IL- 6 and associated signalling can attenuate cachexia progression. Deletion of the IL-6 gene in the APCMin/+ mouse prevented the development of cachexia ${ }^{[4]}$. IL- 6 when secreted by tumour cells can also increase autophagy in myotubes when joined with soluble IL- 6 receptor ${ }^{[45]}$. IL- 6 trans-signalling through the soluble IL-6R has the potential to amplify IL- 6 signalling in the cachectic patient and has been shown to be involved in cross-talk between tumour, muscle and adipose tissue in genetic mouse models of pancreatic cancer cachexia ${ }^{[46]}$. Autophagy and increasing IL- 6 levels have been associated with poor prognosis and weight loss in lung cancer patients ${ }^{[45]}$. It has also been shown to be the key cytokine that regulates the hepatic acute phase response in patients with pancreatic cancer cachexia ${ }^{[47]}$. IL-6 remains a promising therapeutic target in cancer cachexia but a better understanding of its direct and indirect effects, as well as tissue specific actions, is required.

\section{CYTOKINE GENOTYPE}

The presence and concentration of (potentially) pro-cachectic cytokines in cancer patients appear to be dependent not only on the type of tumour, but also on the burden of disease present, and patient specific factors such as age, sex and genotype. It is still not fully understood why patients with the same histological disease may vary with regards to the presence and severity of cachexia. Genetic variation in immunity is one possible reason. Specific single nucleotide polymorphisms in the $I L-1, I L-6$ and $I L-10$ genes have been associated with cachexia in gastrointestinal cancers ${ }^{[48]}$. The $1082 \mathrm{G}$ allele in the IL-10 promoter was validated in an independent cohort. This was shown to be more prevalent in Myc/mTOR-driven mouse models of cachexia as well as cachectic colorectal cancer patients ${ }^{[48]}$. The $\mathrm{C}$ allele of the rs6136 polymorphism in the P-selectin gene has also been associated with weight loss and low CT muscularity in a large group of cancer patients ${ }^{[49]}$. These results suggest a role for the immune system in the complex presentation of cachexia.

\section{CELLS}

\section{Myeloid derived suppressor cells}

Many studies have now suggested that tumour infiltrating immune cells (those which are mainly of myeloid origin) are able to differentiate into cells which then promote tumour growth and metastasis 
through their ability to induce systemic inflammation ${ }^{[50]}$. Tumours can grow through myelopoiesis and the successful evasion of tumour cells from both the innate and adaptive immune systems ${ }^{[51]}$. However, the progression of cancers appears dependent on tumour-associated myeloid cells through their ability to promote angiogenesis and tissue remodelling ${ }^{[52]}$. This apparent immunosuppression has been linked to the development of cachexia in very few studies, despite tumour-induced immunosuppression being well documented in the literature ${ }^{[53]}$.

Myeloid derived suppressor cells (MDSC) may play a role in tumour-related immunosuppression. Tumourinduced amplification of the myeloid compartment leads to the expansion of myeloid-derived suppressor cells. MDSC's are immature myeloid cells in various stages of differentiation, but are not fully differentiated neutrophils, monocytes/macrophages or dendritic cells. They are found in the bone marrow, spleen, lymph nodes and tumours ${ }^{[50]}$. Their mechanisms of action are not fully understood but they are thought to be immunosuppressive and to play a role in the over production of cytokines and inflammatory mediators, which may contribute to cachexia.

MDSC expansion in 4T1 breast carcinoma-bearing mice is associated with the induction of the hepatic acute phase protein response and altered fat metabolism ${ }^{[53]}$. This response is also seen in the C26 and LLC mouse models. The pro-cachectic acute phase response is not seen, however, in $66 \mathrm{C} 4$ subclone of $4 \mathrm{TI}$ mice in which MDSC expansion does not occur ${ }^{[53]}$. Defects in myeloid cell-mediated inflammation has also been shown to result in reduced expression of pro-inflammatory cytokines in the serum of mice with hepatocellular carcinoma ${ }^{[54]}$. Interestingly, this led to enhanced loss of adipose tissue and decreased macrophage number in visceral adipose tissue, suggesting a possible local role for macrophages in the regulation of cancer-induced fat loss ${ }^{[54]}$. These findings imply that myeloid cell-mediated inflammation confers a beneficial function in these rodents, and may provide a potential explanation for the failure of several antiinflammatory drugs in treating cachexia. Although a direct link between the development of cachexia and MDSC's has not been proven, the above studies have suggested that the development of cancer cachexia is partly explained by the expansion of immature myeloid populations associated with the tumour.

\section{TAMs}

TAMs increase tumour progression and metastasis and suppress anti-tumour immune functions ${ }^{[5]}$. Monocytes from blood infiltrate the tumour and are primed by the tumour microenvironment to exert these effects ${ }^{[55]}$. The immune cells within the tumour's microenvironment consist of myeloid-derived suppressor cells, NK cells, dendritic cells, T cells and macrophages ${ }^{[56]}$. It is this infiltrate that contributes to tumour growth and the release of cytokines that promote the pro-cachectic environment. TAMs are recruited via cytokines and chemokines and suppress the activity of cytotoxic T-lymphocytes via programmed cell death 1 ligand 1 (PD-L1) or B7-H4 and other receptors ${ }^{[57]}$. Activated macrophages also secrete cytokines leading to the activation of several complex cascades, thereby increasing inflammatory status ${ }^{[58]}$. The chemokine monocyte chemotactic protein-1 is possibly responsible for the migration of monocytes to adipose tissue in chronic inflammation ${ }^{[59]}$. The mechanisms by which macrophages modulate adipocyte function in cachexia are still unclear.

\section{TILs}

TILs are often found in tumours and are thought to reflect an immune response against the tumour. Many studies report a survival benefit associated with the presence of TIL, suggesting they may delay tumour progression. $\mathrm{CD} 3+$ and $\mathrm{CD} 8+$ TILs in particular have been identified as having a positive effect on $\operatorname{prognosis}^{[60]}$.

\section{IMMUNE SYSTEM BIOMARKERS}

The Neutrophil: Lymphocyte ratio is a prognostic indicator in cancer. Neutrophils increase the inflammatory reaction to pathogens but also interact with cancer cells to produce cytokines and effector 
molecules (e.g., VEGF) that are able to stimulate angiogenesis and promote tumour growth ${ }^{[61]}$. Activated neutrophils can move from the circulation to the tumour site to release reactive oxygen species that in turn can lead to further DNA damage. They also have anti-tumour roles through antibody-mediated cytotoxicity of tumour cells ${ }^{[62]}$.

C-reactive protein is an acute phase non-specific inflammatory marker that can be elevated in response to infection, surgery or malignancy. It is produced by the liver in response to increased levels of IL- 6 released by activated macrophages, as well as IL- 1 and TNF- $\alpha^{[63]}$. The Glasgow Prognostic Score utilises raised CRP and hypalbuminaemia to predict those patients with systemic inflammation as part of cancer cachexia and who have a poor outcome. It has been examined in more than 60,000 patients and has been shown to have independent prognostic value ${ }^{[64]}$.

\section{IMMUNOTHERAPEUTIC AGENTS FOR CANCER CACHEXIA}

Immunotherapeutic agents for cancer cachexia have yielded mixed results. The different forms of immunotherapy are discussed in detail below.

\section{TNF $\alpha$ inhibitors}

There are currently several TNF inhibitors in use for the management of diseases such as rheumatoid arthritis (RA), psoriasis and inflammatory bowel disease, namely etanercept, infliximab and adalimumab ${ }^{[65]}$. These drugs have revolutionised the treatment of RA but have also offered insights into the role that TNF- $\alpha$ plays in cachexia. In RA patients, they attenuate the hepatic acute phase response and, importantly, improve patients quality of life ${ }^{[6,66]}$. They have also been shown recently to prevent worsening of the disease and restore fat free mass ${ }^{[67]}$. These drugs are now used to treat many thousands of patients and have been shown to be effective at blocking TNF- $\alpha$, but are not effective in treating cancer-induced cachexia ${ }^{[62-64]}$. The feature common to all of these diseases is chronic inflammation due to exaggerated production of proinflammatory cytokines. Etanercept has showed some promising results in improving fatigue in a small cohort of cancer patients ${ }^{[68]}$. A phase I/II study was conducted on pancreatic cancer patients comparing etanercept and gemcitabine with gemcitabine alone. A small increase in progression free survival was seen associated with higher plasma IL-10 levels, but there was no significant improvement in 6 month progression-free survival compared with gemcitabine alone ${ }^{[68]}$. A placebo-controlled double-blind trial was also undertaken in 63 patients with incurable malignancy and weight loss of $>2.27 \mathrm{~kg}$ over 2 months or daily intake of $<20$ calories/kg body weight. Weight gain was found to be minimal in both arms with comparable survival times. Treatment was associated with higher neurotoxicity ${ }^{[69]}$. In this trial, therefore, etanercept was not effective in the treatment of cachexia in patients with advanced disease.

Infliximab has been used in a phase II placebo controlled randomised study in patients with stage II-IV pancreatic cancer ${ }^{[70]}$. Patients were given either $3 \mathrm{mg} / \mathrm{kg}$ or $5 \mathrm{mg} / \mathrm{kg}$ infliximab with gemcitabine or placebo with gemcitabine. The mean change in lean body mass was $+0.4 \mathrm{~kg}$ for those on placebo, $+0.3 \mathrm{~kg}$ for those receiving $3 \mathrm{mg} / \mathrm{kg}$ of infliximab, and $+1.7 \mathrm{~kg}$ for those receiving $5 \mathrm{mg} / \mathrm{kg}$ of infliximab. No statistically significant differences were seen, however ${ }^{[70]}$.

Another agent with anti-inflammatory activity is OHR/AVR118, a broad-spectrum peptide-nucleic acid immune modulator that targets both TNF- $\alpha$ and IL- $6{ }^{[71]}$. A phase II study involving patients with advanced cancer and cachexia showed an improvement in anorexia, dyspepsia, strength, and depression ${ }^{[7]]}$.

\section{Anti-IFN $\gamma$ treatments}

Anti IFN $\gamma$ treatments have been effective in reverting cachexia in the LLC mouse model ${ }^{[2]}$. There have been no trials undertaken in cancer patients, mainly due to the fact that this type of therapy requires a dose to completely block the action of IFN $\gamma$, and at present, such a treatment programme would be very expensive. The only trial conducted in patients with cachexia due to sepsis showed no benefit ${ }^{[72]}$. 


\section{IL-1/6 inhibitors}

The IL-1 pathway has been previously targeted in humans with the recombinant human IL-1 receptor antagonist Anakinra and the neutralising monoclonal anti-IL-1 antibody Canakinumab. Anakinra, as previously discussed, has had success in rheumatoid patients but has yet to be trialled in patients with cancer $^{[65]}$. However, a more specific IL-1a human monoclonal antibody, MABp1, has shown promising results in cancer. An initial dose escalation and expansion study was designed using MABp ${ }^{[73]}$. The first dose escalation study was performed in patients with refractory cancer to assess its safety and tolerability. It identified an optimal intravenous dose which was then used in the following phase II study of forty-two patients $^{[73]}$. Median plasma IL- 6 concentrations decreased from baseline to week $8(P=0.08)$. Of those 30 patients who had an assessment of body composition, lean mass increased significantly by $1.02 \pm 2.24 \mathrm{~kg}$ $(P=0.02)^{[73]}$. It was then compared to megestrol acetate in patients with advanced colorectal cancer and $>5 \%$ weight loss. Those in the MABp1 treatment arm showed a trend towards increased survival ${ }^{[7]}$. A placebo-controlled, double blind phase III study in 333 patients with advanced colorectal cancer was then undertaken which resulted in increased lean body mass as well as symptom relief (pain, anorexia, fatigue) ${ }^{[75]}$.

IP1510 is a synthetic peptide IL-1 receptor antagonist. Pre-clinical studies found it to have low toxicity, and to be a potential effective treatment for cachexia. It was then trialled in advanced gynaecological cancer patients where it was well tolerated, and it significantly improved patient anorexia, depression and physical performance. Weight stabilisation or gain was seen in 17 of the 26 enrolled patients ${ }^{[76]}$. Interpretation of the current data is limited because the study was neither randomised nor controlled. However, further larger trials are to be initiated targeting IL1 in cancer cachexia ${ }^{[74]}$.

Studies involving IL-6 antibodies have been undertaken in patients with advanced non-small cell lung cancer. The humanised monoclonal IL-6 antibody Clazakizumab [ALD518] has shown beneficial results in increasing haemoglobin levels and preventing loss of lean body mass. Fatigue scores were also improved compared with controls ${ }^{[77]}$. There are, however, no phase III trials underway.

Immunotherapeutic agents continue to be a promising treatment for cancer cachexia and may be added to the multi-modal management approach for this complex syndrome.

\section{Standard cancer immunotherapy}

Anti-cancer immunotherapy including bermekimab above has been shown to improve outcomes in a range of tumour types, including melanoma, lung and bladder cancers, many of which respond poorly to traditional agents. Some of these therapies are, however, poorly understood. Patients with cancer cachexia have been shown to respond poorly to some immunotherapies such as immune check point inhibitor therapy, likely due to elevated clearance or the establishment of primary resistance ${ }^{[78]}$. In two large clinical trials involving patients with melanoma and non-small cell lung cancer, there was a paradoxical association between plasma clearance of Pembrolizumab [a programmed cell death protein inhibitor (PD-1)] and poor overall survival. Those patients who responded poorly were noted to have reduced body weight and low albumin, suggesting that the presence of cachexia rendered these patients unable to respond to Pembrolizumab ${ }^{[76]}$. The hypoalbumaemia was hypothesised to explain the elevated plasma clearance, and therefore the dose was increased in these patients to counteract this apparent resistance, but it did not result in improved outcomes. Studies in lung cancer patients treated with immunotherapy have shown that decreases in pre-treatment BMI, weight loss and high neutrophil:lymphocyte ratio were associated with significantly shorter progression-free survival ${ }^{[79]}$. However, other studies in lung cancer patients have also shown that two thirds of those receiving PD-1 and PD-L1 immune check point inhibitors experienced stability or an increase in their skeletal muscle index ${ }^{[80]}$. Thus, although at first glance immunotherapy would seem to be a natural antidote to cancer cachexia, it is difficult to unravel the clinical impact of immunotherapy from the known adverse outcomes of any cancer patients with poor nutritional status. 
These studies therefore raise the possibility that immunotherapies could represent effective anti-cachexia agents but that synchronous multimodal and nutritional anti-cancer treatments may be required to establish or enhance their overall effectiveness.

A key consideration in using immunotherapy may be the inflammatory status of the host. It has been demonstrated that the host inflammatory status influences the efficacy of therapy with inflamed patients most likely to benefit from therapies with an anti-inflammatory mode of action ${ }^{[81]}$. Similar to the call to "stage the tumor, stage the host" ${ }^{[82]}$ it is now key that treatment stratification is based on the inflammatory status of the patient and this is now being used as a mandatory measure in clinical trials in some tumour groups ${ }^{[83]}$. It is clear that whilst immunotherapies as a treatment for cancer cachexia, there is a necessity to ensure patients who receive these are those who are most likely to benefit.

\section{CONCLUSION}

The pathogenesis of cancer cachexia is highly dependent on the patient's immune response. The interplay between inflammatory cytokines (such as TNF- $\alpha$, IFN $\gamma$ and interleukins) and pro-cachectic factors contributes to the complex aetiology. These cytokines are produced by the host in response to the tumour, as well as by the tumour itself. Many treatments have tried to regulate the immune response in cachexia but have largely been unsuccessful, perhaps in part due to the multifactorial nature of cachexia, and the observed heterogeneity of patient factors. Large-scale clinical studies are needed to prove whether neutralisation of deleterious cytokines or direct receptor antagonism in combinatorial treatment regimens is an effective therapeutic approach to improve patient outcomes or to reverse muscle loss in cancer cachexia.

\section{DECLARATIONS}

\section{Authors' contributions}

Drafted the manuscript: Miller J

Critically revised the manuscript and gave final approval for the version to be published: Laird BJA, Skipworth RJE

\section{Availability of data and materials}

Not applicable.

\section{Financial support and sponsorship}

Miller J is supported by Cancer Research UK and the Royal College of Surgeons of Edinburgh. Skipworth RJE is supported by an NHS Research for Scotland (NRS) funded post.

\section{Conflicts of interest}

The authors declared that there are no conflicts of interest.

\section{Ethical approval and consent to participate}

Not applicable.

\section{Consent for publication}

Not applicable.

\section{Copyright}

(c) The Author(s) 2019. 


\section{REFERENCES}

1. Fearon K, Strasser F, Anker SD, Bosaeus I, Bruera E, et al. Definition and classification of cancer cachexia: an international consensus. Lancet Oncol 2011;12:489-95.

2. Fearon KC, Voss AC, Hustead DS; Cancer Cachexia Study Group. Definition of cancer cachexia: effect of weight loss, reduced food intake, and systemic inflammation on functional status and prognosis. Am J Clin Nutr 2006;83:1345-50.

3. Porporato PE. Understanding cachexia as a cancer metabolism syndrome. Oncogenesis 2016;5:e200.

4. Douglas E, McMillan DC. Towards a simple objective framework for the investigation and treatment of cancer cachexia: the Glasgow Prognostic Score. Cancer Treat Rev 2014;40:685-91.

5. Arends J, Bachmann P, Baracos V. ESPEN guidelines on nutrition in cancer patients. Clin Nutr 2017;36:11-48.

6. Laird B, Fallon M. Treating cancer cachexia: an evolving landscape. Ann Oncol 2017;28:2055-6.

7. Shurin MR. Cancer as an immune-mediated disease. ImmunoTargets Ther 2012;1:1-6.

8. de Matos-Neto E, Lima J, dePeriera W, Figuerêdo R, Riccardi D, et al. Systemic inflammation in cachexia - is tumor cytokine expression profile the culprit? Front Immunol 2015;6:1-11.

9. Baracos VE, Martin L, Korc M, Guttridge DC, Fearon KCH. Cancer-associated cachexia. Nat Rev Dis Primer 2018;4:17105.

10. Tracey K, Lowry SF, Cerami A. Cachectin: a hormone that triggers acute shock and chronic cachexia. J Infect Dis 1988;157:413-20.

11. Sharma M, Kambadur R, Sriram S, Lokireddy S, McFarlane CD. Molecular targets of cancer cachexia: Opportunities for pharmanutritional approaches. PharmaNutrition 2014;2:126-8.

12. Sherry BA, Gelin J, Fong Y, Marano M, Wei H, et al. Anticachectin/tumor necrosis factor-alpha antibodies attenuate development of cachexia in tumor models. FASEB J 1989;3:1956-62.

13. Hayden MS, Ghosh S. Regulation of NF-kB by TNF family cytokines. Semin Immunol 2014;26:253-66.

14. Cawthorn W, Sethi J. TNF- $\alpha$ and adipocyte biology. FEBS Lett 2008;9:117-31.

15. Noguchi Y, Vydelingum N, Younes R, Fried S, Brennan M. Tumor-induced alterations in tissue lipoprotein lipase activity and mRNA levels. Cancer Res 1991;51:863-9.

16. Torelli G, Meguid M, Moldawer LL, Edwards C, Kim H, et al. Use of recombinant human soluble TNF receptor in anorectic tumor-bearing rats. Am J Physiol 1999;277:850-5.

17. Llovera M, García-Martínez C, Lopez-Soriano J, Agell N, Lopez-Soriano FJ, et al. Protein turnover in skeletal muscle of tumour-bearing mice overexpressing the soluble TNF receptor-1. Cancer Lett 1998;130:19-27.

18. Yu Z, Li P, Hannink M, Stamler J, Yan Z. Fiber type-specific nitric oxide protects oxidative myofibers against cachectic stimuli. PLoS One 2008;3:e2086.

19. Tisdale MJ. Biology of cachexia. J Natl Cancer Inst 1997;89:1763-73.

20. Thompson M, Cooper S, Parry B, Tuckey J. Increased expression of the mRNA for hormone-sensitive lipase in adipose tissue of cancer patients. Biochim Biophys Acta 1993;1180:236-42.

21. Karayiannakis A, Syrigos K, Polychronidis A, Pitiakoudis M, Bounovas A, et al. Serum levels of tumor necrosis factor- $\alpha$ and nutritional status in pancreatic cancer patients. Anticancer Res 2001;21:1355-8.

22. Maltoni M, Fabbri L, Nanni O, Scarpi E, Pezzi L, et al. Serum levels of tumour necrosis factor alpha and other cytokines do not correlate with weight loss and anorexia in cancer patients. Support Care Cancer 1997;5:130-5.

23. Hou YC, Wang CJ, Chen HY, Wang HC, Tung HL, et al. Elevated serum interleukin-8 level correlates with cancer-related cachexia and sarcopenia: an indicator for pancreatic cancer outcomes. J Clin Med 2018;7:502.

24. Haller O, Kochs G, Weber F. The interferon response circuit: Induction and suppression by pathogenic viruses. Virology 2006;344:119-30.

25. Mah A, Cooper M. Metabolic regulation of natural killer cell IFN- $\gamma$ production. Crit Rev Immunol 2016;36:131-47.

26. Stanton S, Disis M. Clinical significance of tumor-infiltrating lymphocytes in breast cancer. J Immunother Cancer 2016;4:59.

27. Palata-Salaman C. Interferons and central regulation of feeding. Am J Physiol 1993;263:1222-7.

28. Matthys P, Dukmans R, Proost P, Van Damme J, Heremans H, et al. Severe cachexia in mice inoculated with interferon- $\gamma$-producing tumor cells. Int J Cancer 1991;49:77-82.

29. Matthys P, Heremans H, Opdenakker G, Billiau A. Anti-interferon-gamma antibody treatment, growth of Lewis lung tumours in mice and tumour associated cachexia. Eur J Cancer 1991;27:182-7.

30. Langstein H, Doherty G, Fraker D, Buresh C, Norton JA. The roles of gamma-interferon and tumor necrosis factor alpha in an experimental rat model of cancer cachexia. Cancer Res 1991;51:2302-6.

31. Gregoire F, Broux N, Hauser N, Heremans H, Van Damme J, et al. Interferon-gamma and interleukin-1 beta inhibit adipoconversion in cultured rodent preadipocytes. J Cell Physiol 1992;151:300-9.

32. Yeh S, Schuster M. Geriatric cachexia: the role of cytokines. Am J Clin Nutr 1999;70:183-97.

33. Dinarello C. Interleukin-1 in the pathogenesis and treatment of inflammatory diseases. Blood 2011;117:3720-32.

34. Hardardottir I, Doerrler W, Feingold K, Grunfeld C. Cytokines stimulate lipolysis and decrease lipoprotein lipase activity in cultured fat cells by a prostaglandin independent mechanism. Biochem Biophys Res Commun 1992;186:237-43.

35. McCarthy H, Dryden S, Williams G. Interleukin-1 beta-induced anorexia and pyrexia in rat: relationship to hypothalamic neuropeptide Y. Am J Physiol 1995;269:852-7.

36. Sato T, Laviano A, Meguid M, Chen C, Rossi Fanelli F, et al. Involvement of plasma leptin, insulin and free tryptophan in cytokine-induced anorexia. Clin Nutr 2003;22:139-46.

37. Costelli P, Llovera M, Carbo N, García-Martínez C, Lopez-Sorianoq F, et al. Interleukin-1 receptor antagonist (IL-1ra) is unable to reverse cachexia in rats bearing an ascites hepatoma (Yoshida AH-130). Cancer Lett 1995;95:33-8.

38. Strassmann G, Masui Y, Chizzonite R, Fong M. Mechanisms of experimental cancer cachexia. Local involvement of IL-1 in colon-26 tumor. J Immunol 1993;150:2341-5. 
39. Deans DAC, Wigmore SJ, Gilmour H, Paterson-Brown S, Ross JA, et al. Elevated tumour interleukin-1 $\beta$ is associated with systemic inflammation: a marker of reduced survival in gastro-oesophageal cancer. Br J Cancer 2006;95:1568-75.

40. Wellenstein M, Coffelt S, Duits D, Miltenburg M, Slagter M, et al. Loss of p53 triggers WNT-dependent systemic inflammation to drive breast cancer metastasis. Nature 2019;572:538-42.

41. Scheede-Bergdahl C, Watt H, Trutschnigg B, Kilgour R, Haggarty A, et al. Is IL-6 the best pro-inflammatory biomarker of clinical outcomes of cancer cachexia? Clin Nutr 2012;31:85-8.

42. Zhang D, Zheng H, Zhou Y, Tang X, Yu B, et al. Association of IL-1beta gene polymorphism with cachexia from locally advanced gastric cancer. BMC Cancer 2007;7:45.

43. Miller A, McLeod L, Alhayyani S, Szczepny A, Watkins D, et al. Blockade of the IL-6 trans-signalling/STAT3 axis suppresses cachexia in Kras-induced lung adenocarcinoma. Oncogene 2017;36:3059-66.

44. White J. IL-6, cancer and cachexia: metabolic dysfunction creates the perfect storm. Translational cancer research. Transl Cancer Res 2017;6:280-5.

45. Pettersen K, Andersen S, Degen S, Tadini V, Grosjean J, et al. Cancer cachexia associates with a systemic autophagy-inducing activity mimicked by cancer cell-derived IL-6 trans-signalling. Sci Rep 2017;7:2046.

46. Rupert J, Bonetto A, Narasimhan, Koniaris L. IL-6 trans signaling among tumour, muscle and fat mediates pancreatic cancer cachexia. J Cachexia Sarcopenia Muscle 2018;9:1121-84.

47. O'Riordain M, Falconer J, Maingay J, Fearon K, Ross J. Peripheral blood cells from weight-losing cancer patients control the hepatic acute phase response by a primarily interleukin-6 dependent mechanism. Int J Oncol 1999;15:823-7.

48. Hishida A, Okugawa Y, Morimoto Y, Shirai Y, Okamoto K, et al. Genetic influence of cytokine polymorphisms on the clinical outcome of Japanese gastrointestinal cancer patients in palliative care. Oncol Lett 2019;17:623-9.

49. Johns N, Stretch C, Tan BHL, Solheim TS, Sørhaug S, et al. New genetic signatures associated with cancer cachexia as defined by low skeletal muscle index and weight loss. J Cachexia Sarcopenia Muscle 2017;8:122-30.

50. Marvel D, Gabrilovich D. Myeloid-derived suppressor cells in the tumor microenvironment: expect the unexpected. J Clin Invest 2015;125:3356-64.

51. Gajewski T, Schreiber H, Fu Y. Innate and adaptive immune cells in the tumor microenvironment. Nat Immunol 2013;14:1014-22.

52. Guo C, Buranych A, Sarkar D, Fisher P, Wang X. The role of tumor-associated macrophages in tumor vascularization. Vasc Cell 2013;5:20.

53. Cuenca A, Cuenca A, Winfield R, Joiner D, Gentile L, et al. Novel role for tumor-induced expansion of myeloid derived cells in cancer cachexia. J Immunol 2015;192:6111-9.

54. Erdem M, Moeckel S, Jumpertz S, John C, Fragoulis A, et al. Macrophages protect against loss of adipose tissue during cancer cachexia. J Cachexia Sarcopenia Muscle 2019; doi: 10.1002/jcsm.12450.

55. Tang X, Mo C, Wang Y, Wei D, Xiao H. Anti-tumour strategies aiming to target tumour-associated macrophages. Immunology 2013;138:93104.

56. Lindau D, Gielen P, Kroesen M, Wesseling P, Adema G. The immunosuppressive tumour network: myeloid-derived suppressor cells, regulatory T cells and natural killer T cells. Immunology 2013;138:105-15.

57. Noy R, Pollard J. Tumor-associated macrophages: from mechanisms to therapy. Immunity 2015;41:49-61.

58. Laine A, Lyengar P, Pandita T. The role of inflammatory pathways in cancer-associated cachexia and radiation resistance. Mol Cancer Res 2013;11:967-72

59. Deshmane S, Kremlev S, Amini S, Sawaya B. Monocyte chemoattractant protein-1 (MCP-1): an overview. J Interferon Cytokine Res 2009;29:313-26.

60. Gooden M, de Bock G, Leffers N, Daemen T, Nijman H. The prognostic influence of tumour inflitrating lymphocytes in cancer: a systematic review with meta analysis. Br J Cancer 2011;105:93-103.

61. Albini A, Bruno A, Noonan DM, Mortara L. Contribution to tumour angiogenesis from innate immune cells withing the tumour microenvironment: implications for Immunotherapy. Front Immunol 2018;9:527.

62. Singel KL, Segal B. Neutrophils in the tumour microenvironment: trying to heal the wound that cannot heal. Immunol Rev 2016;273:329-43.

63. Sproston NR, Ashworth JJ. Role of C-reactive protein at sites of inflammation and infection. Front Immunol 2018;9:754.

64. Laird BJ, Kaasa S, McMillan DC, Fallon MT, Hjermstad MJ, et al. Prognostic factors in patients with advanced cancer: a comparison of clinicopathological factors and the development of an inflammation-based prognostic system. Am Assoc Cancer Res 2013;19:5456-64.

65. Siebert S, Tsoukas A, Robertson J, McInnes I. Cytokines as therapeutic targets in rheumatoid arthritis and other inflammatory diseases. Pharmacol Rev 2015;67:280-309.

66. Maini R, Breedveld F, Kalden J, Smolen J, Furst D, et al. Sustained improvement over two years in physical function, structural damage, and signs and symptoms among patients with rheumatoid arthritis treated with infliximab and methotrexate. Arthritis Rheum 2004;50:1051-65.

67. Marcora S, Chester K, Mittal G, Lemmey A, Maddison P. Randomized phase 2 trial of anti-tumor necrosis factor therapy for cachexia in patients with early rheumatoid arthritis. Am J Clin Nutr 2006;84:1463-72.

68. Wu C, Fernandez S, Criswell T, Chidiac T, Guttridge D, et al. Disrupting cytokine signaling in pancreatic cancer: a phase I/II study of etanercept in combination with gemcitabine in patients with advanced disease. Pancreas 2013;42:813-8.

69. Jatoi A, Dakhil S, Nguyen P, Sloan J, Kugler J, et al. A placebo-controlled double blind trial of etanercept for the cancer anorexia/weight loss syndrome: results from N00C1 from the North Central Cancer Treatment Group. Cancer 2007;110:1396-403.

70. Wiedenmann B, Malfertheiner P, Friess H, Ritch P, Arseneau J, et al. A multicenter, phase II study of infliximab plus gemcitabine in pancreatic cancer cachexia. J Support Oncol 2008;6:18-25.

71. Chasen M, Hirschman S, Bhargava R. Phase II study of the novel peptide-nucleic acid OHR118 in the management of cancer-related anorexia/cachexia. J Am Med Dir Assoc 2011;12:62-7.

72. Tracey K. TNF and other cytokines in the metabolism of septic shock and cachexia. Clin Nutr 1992;11:1-11.

73. Hong D, Hui D, Bruera E, Janku F, Naing A, et al. MABp1, a first-in-class true human antibody targeting interleukin-1 $\alpha$ in refractory 
cancers: an open-label, phase 1 dose-escalation and expansion study. Lancet Oncol 2014;15:656-66.

74. Fisher G. A phase III study of xilonix in refractory colorectal cancer patients with weight loss. J Clin Oncol 2015;33:685-5.

75. Hickish T, Andre T, Wyrwicz L, Saunders M, Sarosiek T, et al. MABp1 as a novel antibody treatment for advanced colorectal cancer: a randomised, double-blind, placebo-controlled, phase 3 study. Lancet Oncol 2017;18:192-201.

76. Paspaliaris V, Langan B, DeAndrea R, Wood J, Tsouvelekas A, et al. Phase I/II study of IP-1510 a novel interleukin-1 receptor antagonist in the management of cancer-related cachexia. J Cachexia Sarcopenia Muscle 2011;2:261.

77. Bayliss T, Smith J, Schuster M, Dragnev K, Rigas J. A humanized anti-IL-6 antibody (ALD518) in non-small cell lung cancer. Expert Opin Biol Ther 2011;11:1663-8

78. Coss C, Clinton S, Phelps M. Cachectic cancer patients: immune to check-point inhibitor therapy? Clin Cancer Res. 2018;24:5787-9.

79. Kollipara R, Fughhi I, Batus M, Basu S, Borgia J, et al. Decreasing BMI/weight immediately prior to starting anti-PD-1/PDL-1 monoclonal antibodies for treatment for stage IV non-small cell lung cancer is associated with shorter progression-free survival. J Clin Oncol 2019;37:e20710

80. Multani M, Tarhoni I, Fughhi I, Basu S, Batus M, et al. Changes in skeletal muscle mass during PD-1 and PD-L1 checkpoint inhibitor therapy in advanced-stage non-small cell lung cancer patients. J Clin Oncol 2019;37:e14061.

81. Dolan RD, Laird BJA, Horgan PG, McMillan DC. The prognostic value of the systemic inflammatory response in randomised clinical trials in cancer: a systematic review. Crit Rev Oncol Hematol 2018;132:130-7.

82. Roxburgh CSD, McMillan DC. Cancer and systemic inflammation: treat the tumour and treat the host. Br J Cancer 2014;110:1409-12.

83. Ter Veer E, van Rijssen L, Besselink M. Consensus statement on mandatory measurements in pancreatic cancer trials (COMM-PACT) for systemic treatment of unresectable disease. Lancet Oncol 2018;19:e151-60. 